\title{
SPR METHOD : REHABILITATION TECHNOLOGIES TO REVIVE DECREPIT PIPELINES
}

\author{
Toshiyuki Deguchi \\ Tokyo Metropolitan Sewerage Service Corporation \\ 6-2 Otemachi, 2-chome, Chiyoda-ku, Tokyo, \\ 100-8699 Japan \\ E-mail : deguchi@tgs-sw.co.jp
}

\author{
Hamao Yamashiro \\ Adachi Construction and Industry Co.Ltd \\ 12-8 Iriya, 8-chome, Adachi-ku, Tokyo \\ 121-0836 Japan \\ E-mail : amashiro@adachi-tokyo.co.jp
}

\author{
Hiroshi Sugahara \\ Sekisui Chemical Co.Ltd \\ 3-7 Toranomon 2-chome Minato-ku,Tokyo \\ 105-8450 Japan \\ E-mail:sugahara002@sekisui.jp
}

\begin{abstract}
In the SPR (Sewage Pipe Renewal) method, a rigid PVC liner is formed inside an existing pipe by using a specially designed winding machine that is placed inside the existing pipe. A rigid PVC profile strip is fed through a manhole entrance above ground, and the winding machine is used to wind and interlock the profiles together to form a liner. Rehabilitation technologies are needed that can cope with various existing installation site conditions; i.e. long or curved pipelines, with round, square or horseshoe shaped crossections. Under such circumstances, we have developed a new technology to form the PVC liner in which self running winding machenes travel around a frame that is set inside the existing pipeline, and which is made to conform to the interior cross sectional shape of the pipe.
\end{abstract}

Keywords : No-dig method, Self driving machine, Profile, Free Cross-Section SPR Method, Heart SPR Metho

\section{INTRODUCTION}

The 20th century was "the Age of Construction" in Japan. With the goal of achieving a comparable standard of living with the USA and Europe, a huge amount of public works infrastructure development was carried out, and a fairly comfortable living environment has been structured.

The coverage ratio of sewerage, one of the fundamentals of infrastructure, has reached $68 \%$. The total length of installed sewers has reached about $370,000 \mathrm{~km}$, and is still increasing year by year.

It is estimated that 8,000 $\mathrm{km}$ of these sewers have exceeded their useful life and are aged and deteriorated. In addition to such sewers, there are other public pipelines to carry agricultural and industrial water or water for power stations, etc., that have also become aged and deteriorated or damaged, and are in need of repair and rehabilitation. In this sense, the 21st century is "the Age of Maintenance", the time to repair these pipelines and maintain them in good condition.

Under such circumstances, the SPR method, which originated with Rib Loc's technology, was first implemented in 1986 to rehabilitate a small diameter sewer as a un-excavating rehabilitation method. In 1994, we developed the "Super SPR Method" that has enabled us to rehabilitate medium and large pipelines of over $1000 \mathrm{~mm}$ in diameter, and in 1998 the "Free Cross-Section SPR Method" that has enabled us to rehabilitate non-circular pipelines. Approximately 390,000 meters of pipeline have now been rehabilitated using these SPR methods.

In "Guidelines for Pipe Rehabilitation (draft)" written in Japan in 2000, the SPR method was classified as a "Pipe Forming Method". With the SPR method, an old existing pipeline can be rehabilitated and made into a composite pipeline with a liner and the existing pipeline in one body, which is equal or superior to a new pipeline in its compression strength and durability. Projects rehabilitated by the SPR method have been approved for Government subsidy.

In "the Age of Maintenance", we have developed the "New SPR Method (pipe forming and grouting at the same time)" to flexibly cope with various rehabilitation needs of different applications and also to meet users' and contractors' requests for lower costs, safety, and ease of installation.

In this paper, the SPR Method and the New SPR Method will be introduced.

\section{SPR METHOD}

\subsection{FUNDAMENTALS of SPR Method}

A profile strip (liner material) (Fig.-1) is fed into a liner winding machine which has been previously placed inside the existing pipe through an above ground opening. The winding machine forms a continuous liner inside the existing pipe by interlocking the ribs of the profile strip. The liner is wound inside the existing pipeline for a certain distance (for instance from one manhole to another one), and then the annular gap between the existing pipe and the liner is grouted with special mortar, after both ends of the reach to be grouted have been sealed. This forms a strong composite pipe consisting of the existing pipe/grouting mortar/liner all in one body (Fig.-2). 


\subsection{SELF-RUNNING Winding Machine}

As shown in Fig.-3, a flexible link frame is assembled using a sufficient number of steel links to match the required liner size. The link frame is as flexible as a bicycle chain but is constrained by a rigid internal frame so that it can only bend outward. A driving unit fixed to the link frame is the self-running winding machine, and is of a simple structure. A hydraulic motor is used to move the driving unit. Interlocking rollers are located on both the inside and outside of the link frame. These rollers turn, holding the PVC profile strip between them, and interlock the integrally formed profile locks to form a continuous liner around the inside of the existing pipe. In the case of forming a non-circular liner, the winding machine is driven along the control frame, which is fixed in conformity with the cross-section of the existing pipeline. However, even if a non-circular liner is formed, the PVC profile strips are elastic and attempt to recover a circular shape. Therefore, for a non-circular liner, the PVC profile is enhanced with an attached steel backing strip and combined into a single unit (Fig.-1). By fixing more than two driving units, the steel enhancements are formed to the shape of the liner at the corners. Using the SPR method, winding machines can form liners in certain designated shapes, even in live sewage service, as long as the water level is safe for workers in pipelines.

\subsection{Liner Floatation Prevention and Support Jacks}

After a liner is formed inside the existing pipe, the gap between the liner and the existing pipe is filled with a low viscosity mortar. This process gives the liner buoyancy, and grout injection pressure causes deformation of the liner. Buoyancy and modification power become larger as a caliber becomes large. Therefore, stiffer profiles are used for such work, and support jacks (Fig.-4) are installed at every two meters for pipelines over $800 \mathrm{~mm}$ diameter, thus preventing floatation due to buoyancy, and deformation. Mortar is injected through grout piping from a mortar batching plant at the surface.

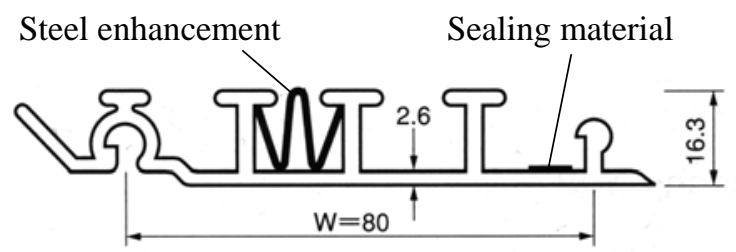

Profile strip interlocking mechanism

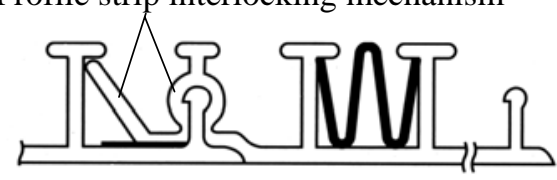

Fig.-1 : Profile strip with Steel Reinforcing Strip in one unit.
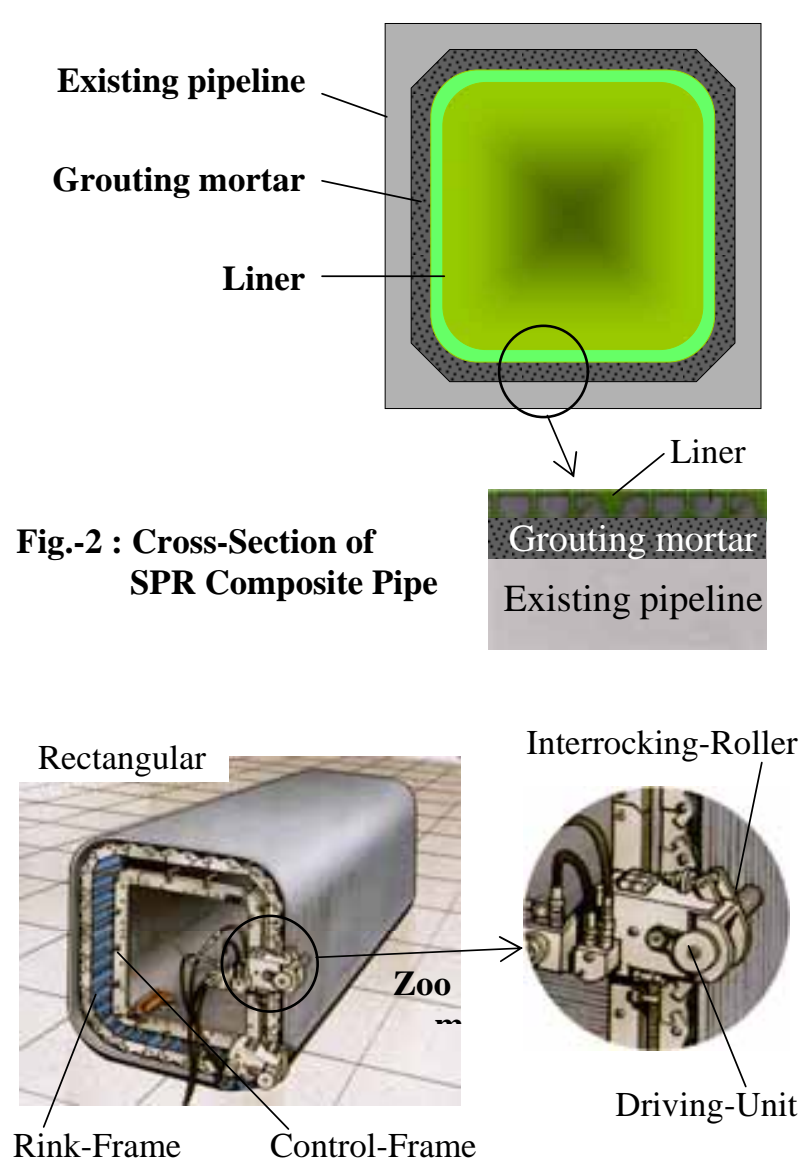

Fig.-3 : Self-Running Winding Machine (shown forming a rectangular liner)

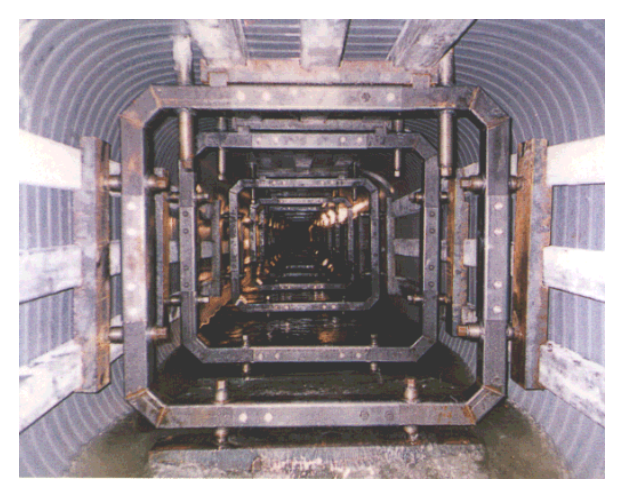

Fig.-4 : Installed Support Jacks

\section{MERITS AND PROBLEMS OF CONVENTIONAL SPR METHOD}

From the beginning of its development, the SPR method was intended to produce liners of certain diameters and shapes by the use of a winding machine and without being influenced by existing conditions such as extremely deteriorated pipes, varied internal diameters, thinned or broken walls, extremely high humidity or by the pipe remaining in service during rehabilitation. 
It was also intended to produce liners with stable and excellent quality in their water tightness, strength, etc.

In addition to sewer rehabilitation, there are quite a number of agricultural and other water pipelines that need to be rehabilitated for the purpose of stopping corrosion or leakage.

The conventional SPR method cannot cope with the need to increase water flow volume which is mostly required for agricultural pipelines while the same or the better water flow volume can be obtained with the new SPR method..

In order to successfully perform a series of multiple processes such as Liner Winding $\rightarrow$ Floatation Prevention and Support Jacks $\rightarrow$ Grouting, experience and know-how are necessary in each process. It is also necessary in project management to be able to smoothly shift over from one process to the next.

Moreover, contractors must make a substantial investment for supporting jacks, grouting equipment, etc. when they begin using the SPR method or expand their capacity. For this reason the "New SPR Method (Simultaneous Liner Forming and Grouting)" has been developed and put into practice. This responds to the needs of users and contractors for lower costs, higher safety and workability.

\section{NEW SPR METHOD (SIMULTANEOUS LINER FORMING AND GROUTING)}

\subsection{BASICS of New SPR Method}

This newly developed method is simply described as "a new SPR method where profiles are wound and made into a liner, and at the same time the gap between the liner and the existing pipe is filled with special mortar."

By omitting the process of fixing support jacks and performing the liner forming and grouting simultaneously, simple and speedy rehabilitation has become possible.

The basic components of a composite pipe by the New SPR method are same as those by the conventional SPR method, making a strong composite pipe (Fig.-2) of an existing pipe, grout mortar, and a liner.

\subsection{LINER Forming Principles (New Self-Running Winding Machine)}

In the conventional SPR method, it was necessary for the outside interlocking roller of a winding machine to travel in the space between the existing pipe and the liner. In the new method the (internal rigid frame) stoppers of the link frame, as explained in section 2.2, are adjusted so that the winding machine can bend inward and center the driving unit. Thus it has become possible to form a liner without the interlocking rollers being interfered with by the existing pipe.

Moreover, by making use of the elastic property of PVC profiles, which was an obstacle in forming a non-circular pipeline, an existing pipe can be lined with a liner in circular or non-circular shapes, controlling its features to recover a circular shape as the winding machine (interlocking rollers) passes (Fig.-5).

As with a conventional self-running winding machine, the new self-running winding machine forms a liner by putting the profile in close contact with the outside surface of the winding machine, therefore, it is possible to form a liner to a specified circumference, and by adjusting the outside circumference of the winding machine, the internal diameter of a liner can be chosen. (In other words, grout thickness can be specified.)

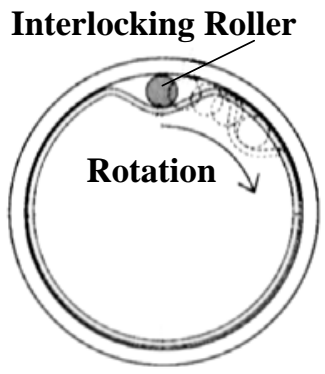

To recover a circular shape by its elasticity

\section{Fig.-5 : Principle of New Self-Running Winding Machine}

\subsection{SIMULTANEOUS Liner Forming and Grouting}

With the improvement of winding machines, it has become possible to line an existing pipe with a liner and to leave no gap, or very narrow gaps, between the existing pipe and a liner.

It is difficult to grout uniformly after a certain distance is lined, when the annular space is small, therefore grouting must be done at the same time as forming a liner.

The grout piping used to fill the gap between an existing pipe and a liner is installed in the space made when a liner is bent inward by an interlocking roller. The mortar injection nozzle is fixed behind the outside interlocking roller, and travels with the outside interlocking roller around the circumference of the liner. The winding machine moves forward by one profile pitch per one turn, and mortar is likewise injected spirally by one profile pitch per one turn. (Fig.-6)

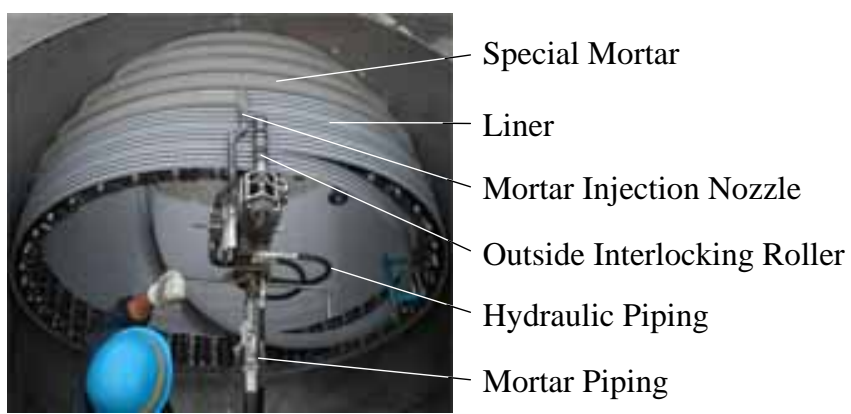

Fig.-6 : Simultaneous Liner Forming and Grouting - 1 
Mortar used for grouting is highly thixotropic and of high viscosity, and it does not drip even if it is applied to a vertical surface, keeping its original form as supplied as shown in Fig.-6.

At a certain speed of liner installation, the highly thixotropic mortar, that is continuously injected at the proper rate, extends and fills the gaps between the existing pipe and the liner, which rebounds to a circular shape due to its elastic property. Any excess mortar flows out forward, as there is no room in the back, and it overlaps with newly supplied mortar in the next turn (Fig.-7).

By continuous repetition of this process, all the gaps are completely filled with mortar. An installation operator monitors the overflow quantity of mortar, and makes adjustment of the supply quantity of mortar.

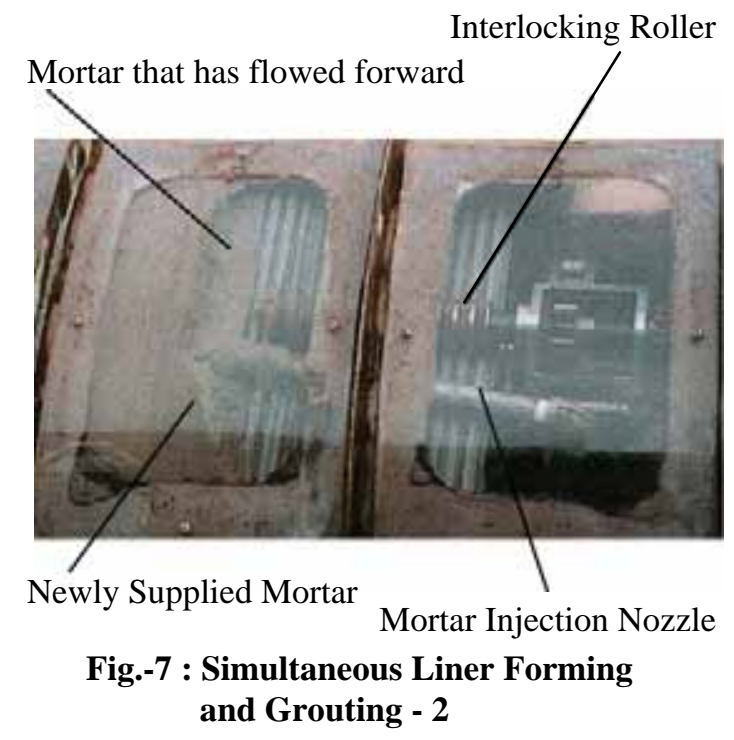

\section{REHABILITATION MATERIALS FOR NEW SPR METHOD}

\subsection{PROFILE with Steel Enhancement}

Profiles used for the New SPR Method are the same as those used for the conventional SPR method. Where the objective of rehabilitation is the recovery of strength equal to or better than a new pipe, "profiles with steel enhancement" are used, in which galvanized steel strips are folded and locked together with the profiles (Fig.-1).

Where the objective of rehabilitation is corrosion-protection or water tightness, and not the recovery of strength, profiles without steel enhancement are used.

\subsection{SPECIAL Mortar for Simultaneous Liner Forming and Grouting}

The special mortar used for simultaneous liner forming and grouting must be highly thixotropic and have enough viscosity not to drip under its own weight after application.
If the mortar is too high in viscosity, it is difficult to pump out to the gaps.

In order to get good structural strength out of the steel enhancement of profiles, mortar must have properties such as strong adhesion to the existing pipe and the liner, high strength, small drying shrinkage, and non-segregation in water.

\section{INSTALLATION EQUIPMENT FOR NEW SPR METHOD}

Necessary equipment for the New SPR Method are a profile winding machine, hydraulic power pack and motor, mortar pump and mixers. No large-scale equipment is necessary. As the viscosity of the mortar is too high to pump from the mixer above ground, the mortar pump is also placed inside the existing pipeline. Mortar is mixed above ground and carried to the mortar pump through the pipeline.

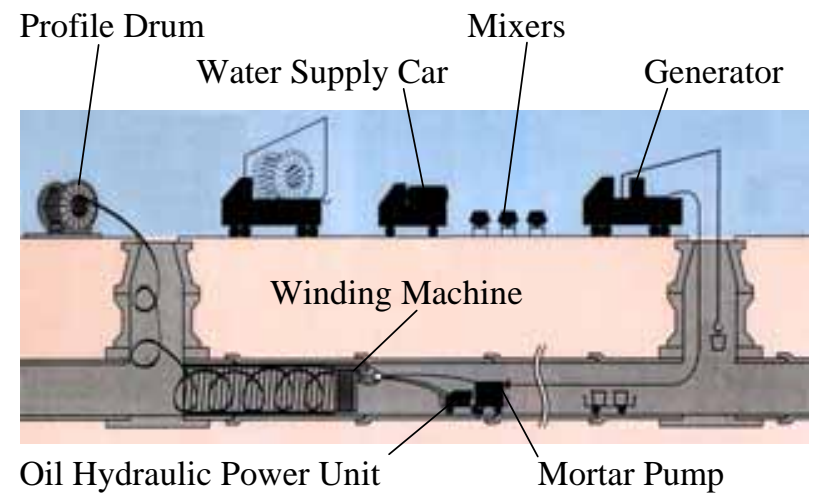

Fig.-8 : Installation Outline of New SPR Method

\section{INSTALLATION EXAMPLES}

Following are actual rehabilitation examples of horseshoe and rectangular pipelines by the SPR method, and circular pipeline by the new SPR method.

\subsection{EXAMPLE of Rectangular Pipeline by SPR Method}

The rehabilitated pipeline was deteriorated after having been in service for a long time. The pipeline also had to be reinforced due to an increase of heavy vehicles traveling over the pipeline. Excavation was difficult because the pipeline was located underneath a state road with heavy traffic.

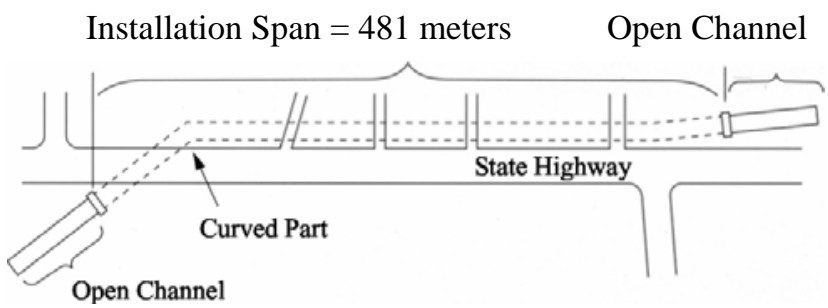

Fig.-9 : Outline of Installation Site 


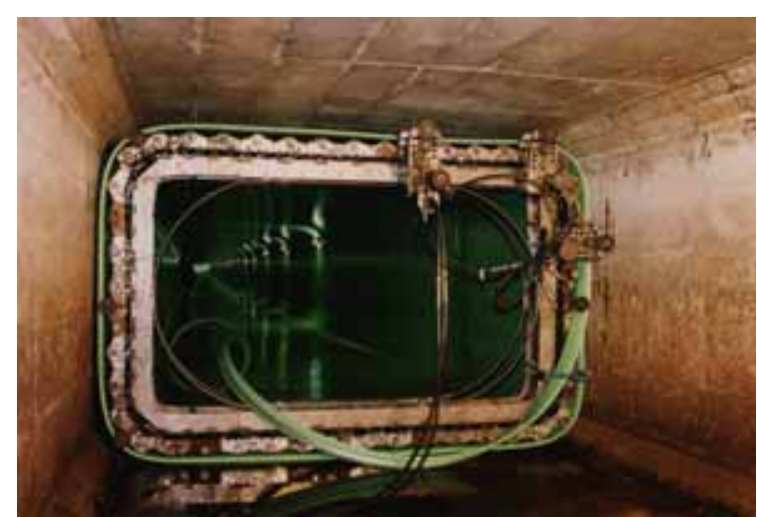

Fig.-10 : View of existing pipeline

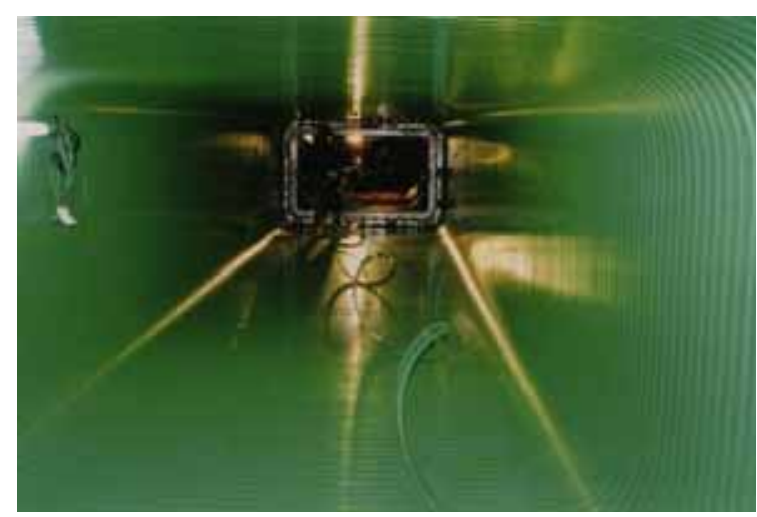

Fig.-11 : View of rehabilitated pipeline

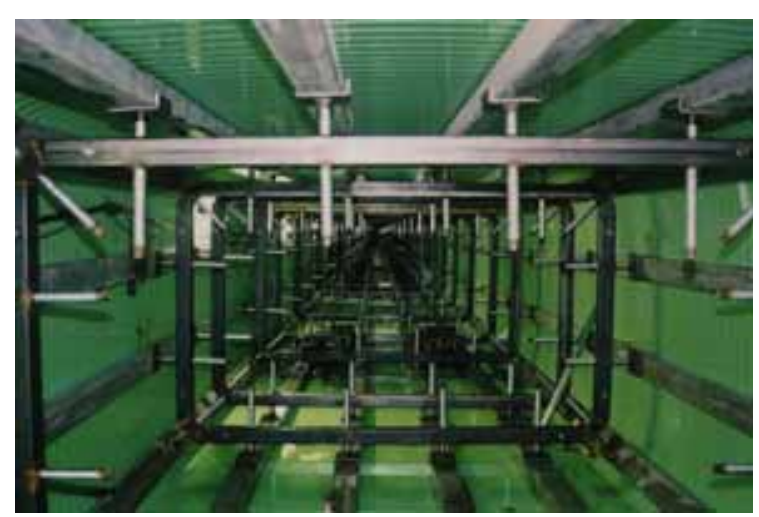

Fig.-12 : Internal Bracing

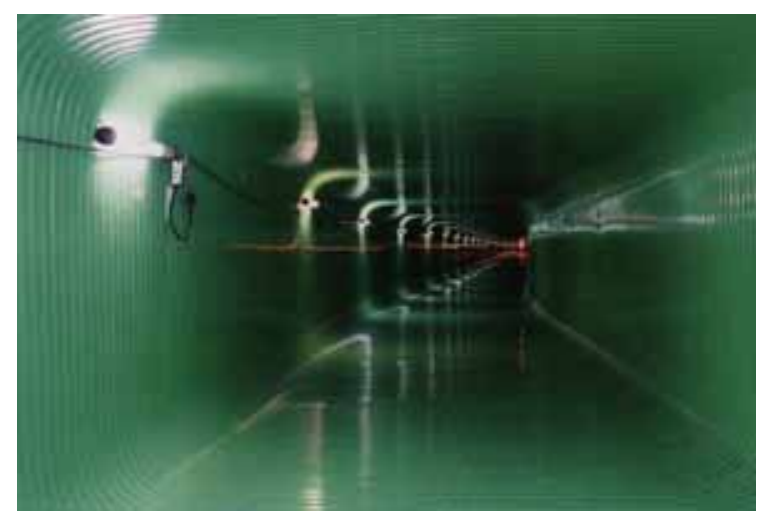

Fig.-13 : Liner after Rehabilitation

\subsection{EXAMPLE of Circular Pipeline Rehabilitated by New SPR Method}

This project rehabilitated a cooling water supply pipeline for turbines at a power station. The pipe had been in service for 30 years. The rust proofing had failed on the inside of the pipeline and the external surface of the pipeline was corroded by sea water. Several pin holes had been repaired by welding steel plate patches in the past. The new SPR method was chosen to rehabilitate this pipe for the following reasons:

- It was possible to rehabilitate the existing pipeline as it was and partial rehabilitation was also possible.

- It was possible to prevent corrosion by grouting materials (mortar). (External surface by rust-proof paint)

- The reduction of cross-section was small and flow volume could be increased.

- Heat expansion and contraction of steel pipe and rehabilitation materials (mortar) are almost same and they behave as one body. (Same as reinforced concrete pipe.)

- The work could be completed within a very short time, while the power station was not operating for periodical maintenance.

(1) Outline of the Work

1) Description of Pipeline

Existing Pipeline: Internal Diameter 1800mm

Liner: Internal Diameter 1750mm

2) Total Length of the Pipeline : about 5 meters

(Equal Diameter Tees)

3) Work Period: about 1 week

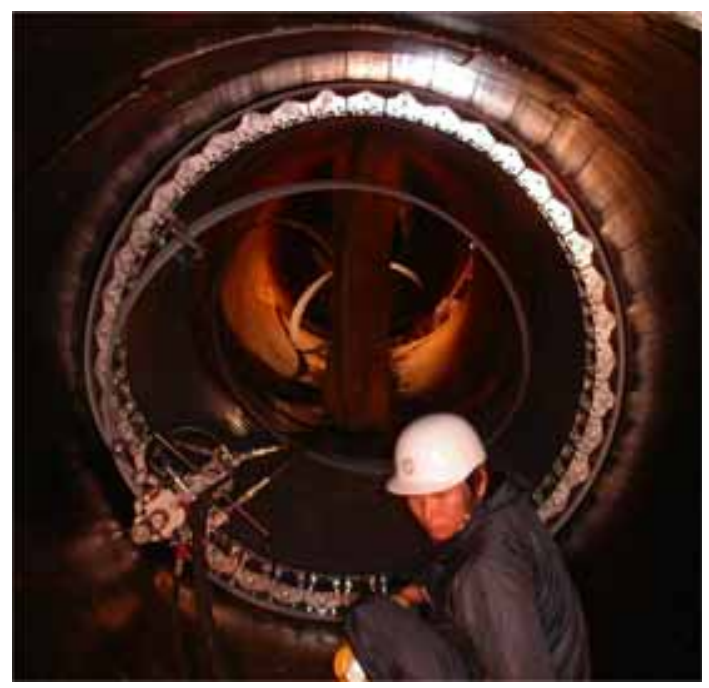

Fig.-14 : Status of Simultaneous Liner Installation and Grouting 


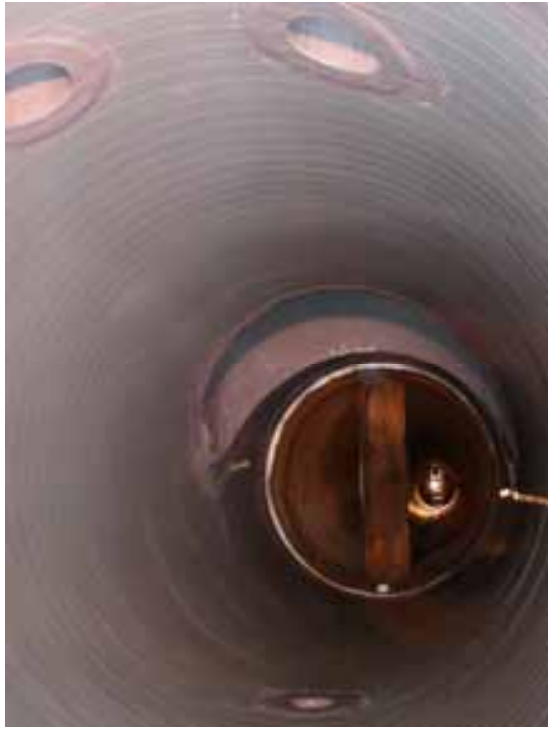

Fig.-15 : Inside the Liner after Rehabilitation

(2) Result of Rehabilitation Work

- Rehabilitation of part of existing pipeline was completed without changing existing equipment.

- The reduction of cross-section was only $50 \mathrm{~mm}$ in diameter, and due to smoother internal surface of the liner, water flow volume increased.

- It would have taken more than 3 months if the pipeline had been replaced, but the work was completed within a very short time during the scheduled maintenance of the plant.

\section{QUALITY OF NEW SPR COMPOSITE PIPE}

The quality of composite pipe rehabilitated by the new SPR method is the same as that of pipe rehabilitated by the conventional SPR method, in smoothness of the liners' internal surface, water tightness, abrasion resistance, chemical resistance, etc. because exactly the same profiles are used in both methods.

Compressive strength and flow capacity of the new SPR composite pipe are shown as follows.

\subsection{COMPRESSION Strength}

Broken reinforced concrete pipe was rehabilitated by the new SPR method. This test was carried out in accordance with the external pressure test method of JSWASA-1 "Reinforced Concrete Pipe for Sewerage" and a comparison of breaking loads was made between new pipes and composite pipes rehabilitated from broken reinforced concrete pipes.(Table-1)

It has been confirmed that a rehabilitated composite pipe has a greater compressive strength than a new pipe.
Table-1 EXTERNAL Pressure Test Cases on Composite Pipe

\begin{tabular}{|c|c|c|c|c|c|c|}
\hline \multirow[b]{2}{*}{$\begin{array}{c}\text { Pipe Diameter } \\
\text { New/Rehabilitated } \\
(\mathrm{mm})\end{array}$} & \multicolumn{3}{|c|}{ Breaking Load $(\mathrm{kN} / \mathrm{m})$} & \multicolumn{3}{|c|}{ Breaking Load Ratio } \\
\hline & $\begin{array}{l}1 \\
\text { New Pipe } \\
\text { JIS Breaking } \\
\text { Load } \\
\text { Standard }\end{array}$ & $\begin{array}{l}\text { (2) } \\
\text { New Pipe } \\
\text { Test Value of } \\
\text { Breaking } \\
\text { Load }\end{array}$ & \begin{tabular}{|l|} 
(3) \\
Composite \\
Pipe \\
Test Value \\
of Breaking \\
Load \\
\end{tabular} & $\begin{array}{l}\text { (2) } \\
\text { (1) }\end{array}$ & $\begin{array}{l}\text { (3) } \\
\text { (1) }\end{array}$ & $\begin{array}{l}\text { (3) } \\
\text { (2) }\end{array}$ \\
\hline $\begin{array}{r}1100 \\
\quad / 1060 \\
\end{array}$ & 65.8 & 141.0 & 160.3 & 2.14 & 2.44 & 1.14 \\
\hline $\begin{array}{l}1500 \\
/ 1460\end{array}$ & 91.3 & 115.9 & 121.0 & 1.27 & 1.32 & 1.04 \\
\hline $\begin{array}{l}2200 \\
/ 2150\end{array}$ & 124 & 158.5 & 200.9 & 1.28 & 1.62 & 1.27 \\
\hline $\begin{array}{l}3000 \\
\quad / 2940\end{array}$ & 148 & 188.3 & 224.8 & 1.27 & 1.52 & 1.19 \\
\hline
\end{tabular}

\subsection{FLOW Capacity}

The internal roughness coefficient of SPR liner has been confirmed to be $\mathrm{n}=0.010$ by measurement of actual installations. By using the roughness coefficient of $n=0.013$ of concrete pipe, flow capacity before and after rehabilitation was calculated and compared based on Manning's formula. (Table-2)

By rehabilitating deteriorated concrete pipe by new SPR method, the flow capacity increased about 1.2 times compared with that of new concrete pipe.

Table-2 COMPARISON of Flow Capacity before and after Rehabilitation (Circular Pipe)

\begin{tabular}{|c|c|c|c|}
\hline \multirow{2}{*}{$\begin{array}{c}\text { Existing Pipe } \\
\text { Diameter } \\
(\mathrm{mm})\end{array}$} & \multirow{2}{*}{$\begin{array}{c}\text { Rehabilitated } \\
\text { Pipe Diameter } \\
\text { (mm) }\end{array}$} & \multicolumn{2}{|c|}{$\begin{array}{l}\text { Flow-ability of Rehabilitated Pipe } \\
\text { (Ratio to Existing Pipe) }\end{array}$} \\
\hline & & Flow Velocity: V & Flow Quantity :Q \\
\hline 800 & 760 & 1.256 & 1.134 \\
\hline 900 & 860 & 1.261 & 1.152 \\
\hline 1000 & 960 & 1.265 & 1.166 \\
\hline 1100 & 1060 & 1.268 & 1.178 \\
\hline 1200 & 1160 & 1.271 & 1.188 \\
\hline 1350 & 1310 & 1.274 & 1.200 \\
\hline 1500 & 1460 & 1.277 & 1.210 \\
\hline 1650 & 1600 & 1.274 & 1.198 \\
\hline 1800 & 1750 & 1.276 & 1.206 \\
\hline 2000 & 1950 & 1.278 & 1.215 \\
\hline 2200 & 2150 & 1.280 & 1.223 \\
\hline 2400 & 2340 & 1.278 & 1.215 \\
\hline 2600 & 2540 & 1.280 & 1.222 \\
\hline 2800 & 2740 & 1.281 & 1.227 \\
\hline 3000 & 2940 & 1.283 & 1.232 \\
\hline
\end{tabular}

\section{CONCLUSION}

By development and implementation of New SPR Method (simultaneous liner forming and grouting), it has become possible to comply with almost any quality requirements for rehabilitation, enabling an increase in water flow volume, that was not possible with the SPR method. It has become possible to choose to line an existing pipeline with a liner, or to form a liner with a designated diameter in an existing pipeline. Therefore, by setting optimum conditions for steel enhancement of profiles and mortar strength and thickness, it has become possible to design optimum rehabilitation specifications, which are more reasonable and economical. Moreover, the New SPR Method has unified installation processes and made it possible to complete its work on daily basis, except for some preparatory or post-work processes, which is accepted as a simple and safe method of rehabilitating deteriorated pipelines. 